\title{
PERFIL DE LIDERANÇA DOCENTE EM UMA INSTITUIÇÃO DE ENSINO SUPERIOR
}

\author{
Arthur Kennedy Nóbrega Silva, Instituto Federal de Educação, Ciência e Tecnologia da \\ Paraíba (IFPB), arthur92adm@gmal.com \\ Islania Andrade de Lira Delfino, Universidade Federal de Campina Grande (UFCG), \\ islania_adm@hotmail.com
}

Gianinni Martins Pereira Cirne, Universidade Federal de Campina Grande (UFCG), gianinnin.martins@gmail.com

\begin{abstract}
RESUMO
Investigações sobre liderança são essenciais para organizações da sociedade como um todo. $\mathrm{O}$ que se percebe em comum nas pesquisas sobre o tema é que se trata de um processo grupal entre dois ou mais indivíduos para o alcance de objetivos. Este estudo teve como objetivo conhecer o perfil de liderança dos docentes dos cursos de Administração e Ciências Contábeis da UFCG - Campus Sousa. Adotou-se a abordagem quantitativa, com características de cunho exploratório e descritivo. Para a coleta dos dados, utilizou-se o MLQ (Multifactor Leadership Questionnaire $\left.{ }^{\circledR}\right)$ de Bass e Avolio (1995), considerando as adaptações de Bigliazzi (2007), sobre as perspectivas de liderança transformacional, transacional e nãotransacional. Os docentes analisados se encaixam no perfil de Liderança Transformacional, com fatores de resultado, que mostraram um ambiente propício para o líder desenvolver suas tarefas.
\end{abstract}

Palavras-chave: Liderança; Docente; Instituição de Ensino Superior.

\section{TEACHING LEADERSHIP IN A HIGHER EDUCATION INSTITUTION}

\section{ABSTRACT}

Leadership research is essential for organizations in society as a whole. What is perceived in common in the research on the subject is that it is a group process between two or more individuals to achieve goals. This study aimed to know the leadership profile of the professors of the courses of Administration and Accounting Sciences of UFCG - Campus Sousa. The quantitative approach was adopted, with exploratory and descriptive characteristics. For the data collection, the MLQ (Multifactor Leadership Questionnaire ${ }^{\circledR}$ ) of Bass and Avolio (1995) was used, considering the adaptations of Bigliazzi (2007), on the perspectives of transformational leadership, transactional and not-transactional. The teachers analyzed fit the profile of Transformational Leadership, with outcome factors, Which showed an environment conducive for the leader to carry out his tasks.

KEY WORDS: Leadership; Teacher; Institution of Higher Education.

\section{EL LIDERAZGO DOCENTE EN UNA INSTITUCIÓN DE ENSEÑANZA SUPERIOR}

\section{RESUMEN}

Las investigaciones sobre el liderazgo son esenciales para las organizaciones de la sociedad en su conjunto. Lo que se percibe en común en las investigaciones sobre el tema es que se trata de un 
proceso grupal entre dos o más individuos para el logro de metas. Este estudio tuvo como objetivo conocer el perfil del liderazgo de los docentes de los cursos de Administración y Ciencias Contables de la UFCG - Campus Sousa. Se adoptó el abordaje cuantitativo, con características de cuño exploratorio y descriptivo. Para la recolección de datos, se utilizó el MLQ (Multifactor Leadership Questionnaire ${ }^{\circledR}$ ) de Bass y Avolio (1995), considerando las adaptaciones de Bigliazzi (2007), sobre las perspectivas de liderazgo transformacional, transaccional y no transaccional. Los docentes analizados encajan en el perfil de Liderazgo Transformacional, con factores de resultado, que mostraron un ambiente propicio para el líder desarrollar sus tareas.

PALABRAS CLAVE: Liderazgo; Docente; Institución de Enseñanza Superior.

\section{INTRODUÇÃO}

A liderança é um fenômeno complexo e muito se foi discutido nos últimos tempos sobre o tema, fazendo surgir várias abordagens e conceitos. Como uma função da administração, desde muito tempo está sob estudos e vem atraindo atenção dos pesquisadores (MAXIMIANO, 2005; SANT'ANNA et al, 2009b).

Pode ser definida como um processo grupal que envolve a influência de indivíduos para o cumprimento de metas (BENNIS, 1996; BOWDITCH, BUONO, 2002; BERGAMINI, 2009) em determinada situação (FIEDLER, 1964; HERSEY; BLANCHARD, 1986). Vergara (2003) percebe a capacidade de influência do líder como um talento. Fiedler (1964) acredita que a situação é que vai direcionar o estilo de liderança a ser adotado.

Nas organizações de fomento à educação, assume uma função de crescente relevância para a transformação dos sistemas educativos em centros de eficácia e qualidade (TRIGO; COSTA, 2008) sendo um ponto fundamental para a evolução e o desenvolvimento institucional (WHITAKER, 2000).

As instituições públicas têm as mesmas características básicas das demais organizações, porém, acrescidas de algumas especificidades como: apego às regras e rotinas, supervalorização da hierarquia, paternalismo nas relações, apego ao poder, entre diversas outras (PIRES; MACÊDO, 2006).

Com a informatização e a necessidade de oferecer um serviço de qualidade superior à sociedade, faz-se necessário uma gestão eficiente e líderes qualificados nas Instituições de Ensino Superior, para que possam extrair ao máximo as competências de sua equipe de trabalho. Neste contexto, a liderança apresenta-se como essencial para orientar os indivíduos e consequentemente as organizações e a sociedade. 
Pensando nisso, essa pesquisa foi realizada em uma instituição pública de ensino superior federal, a Universidade Federal de Campina Grande (UFCG) - Campus Sousa, mais precisamente com os docentes dos cursos de Administração e Ciências Contábeis com o objetivo de conhecer o perfil de liderança desses docentes, verificando sua contribuição para o alcance dos resultados organizacionais.

\section{FUNDAMENTAÇÃO TEÓRICA}

\subsection{LIDERANÇA}

A liderança surgiu nos primórdios das civilizações. O homem sempre buscou estruturas de organização que fossem individuais ou coletivas, que almejavam fins distintos. Isso demandava esforço e dedicação, por isso era necessário que algum indivíduo conseguisse persuadir outros para que as metas estipuladas fossem concretizadas.

Bennis (1996), ressalta que a presença do líder é importante para a eficácia e integridade das organizações, sendo o impulsionador de ideias e conduzindo seu crescimento. Maximiano lembra que a liderança não exige sempre conhecer ou estar próximo do outro.

"Liderança é o processo de conduzir as ações ou influenciar o comportamento e a mentalidade de outras pessoas. Proximidade física ou temporal não é importante para o processo. Um cientista pode ser influenciado por um colega de profissão que nunca viu ou mesmo que viveu em outra época. Líderes religiosos são capazes de influenciar adeptos que estão muito longe e que tem pouquíssima chance de vê-los pessoalmente" (2005, p. 283).

Essa definição induz à observação de comportamentos, e não mais somente de características pessoais. Bergamini (2009) faz uma diferenciação entre as grandes abordagens dividindo-as da seguinte forma: a) aquelas que se voltam para o que o líder é; b) aquelas que se baseiam no que o líder faz; e c) aquelas que levam em conta a análise do ambiente em que ocorre o processo de liderança.

Considerando a conjectura da abordagem contingencial ao acreditar que a liderança representa a interação entre líder, liderados e contexto, percebe-se a importância do seu papel no desenvolvimento das organizações (BOWDITCH; BUONO, 2006; BRYMAN, 2004).

As diferentes percepções dos autores geraram abordagens teóricas que, em épocas específicas, acabaram por influenciar o desenvolvimento do construto liderança, sendo divididas por alguns autores, como Bergamini (2009) e Bowdicth e Buono (2006) em teorias tradicionais e teorias contemporâneas, demonstradas na seção a seguir. 


\subsection{TEORIAS TRADICIONAIS E CONTEMPORÂNEAS}

Nas primeiras abordagens de liderança, seu conceito era relacionado às características de personalidade do indivíduo, que distinguiam líderes de não líderes, sendo que estes seriam natos. Essa abordagem foi denominada de Teoria dos Traços, e a liderança foi justificada sob o aspecto da hereditariedade e por características físicas, psicológicas e sociológicas (BERGAMINI, 2009; GOMES, 2005).

A abordagem comportamental propõe aspectos diferenciados de personalidade por meio de estilos mais eficazes de liderança. Essencialmente, os estilos se diferenciavam pela orientação: para as pessoas ou para as tarefas. (BOWDITCH; BUONO, 2002). As principais críticas a essa teoria foram seu descuido quanto aos aspectos contextuais e informais.

A abordagem contingencial sugere que o líder necessita adaptar seu estilo à situação para conseguir melhores resultados, exercendo relevante influência no processo (BRYMAN, 2004). A principal linha de estudo em relação à essa abordagem foi a proposta de Fiedler (1964), acreditando que o estilo do líder vai sofrer mudanças em relação ao contexto onde está inserido, ou seja, conforme a contingência.

A abordagem transacional teve como grande característica a consideração do processo de influência entre líder e liderado (BERGAMINI, 2009; VAN SETERS; FIELD, 1990). Assim, refere-se ao atendimento do líder em relação ao liderados, para os interesses pessoais dos mesmos.

Na liderança transformacional, o líder guia os seguidores ao desenvolvimento de suas habilidades, fazendo com que os mesmos se comprometam com o coletivo e não apenas com o individual. Pode-se considera-la como um instrumento para influenciar mudanças de pensamentos e atitudes dos membros da organização, estimulando seu comprometimento com os objetivos e estratégias. Esse estilo de liderança se opõe ao estilo transacional, compreendido como um estilo de troca de favores entre líder e liderados.

Destaca-se portanto que o desenvolvimento do construto liderança estabelece relação com a evolução das teorias aqui mencionadas, que não se excluem. Ao contrário, se complementam. A partir delas, surge a necessidade de estudar a liderança em outros contextos, como é o caso do ambiente educacional, abordado na seção a seguir. 


\subsection{LIDERANÇA DOCENTE}

O papel dos professores de inspirar colegas e alunos para a melhoria das suas práticas pode ser identificado como liderança docente. De acordo Zanotto et al (2016, p. 4) "liderança docente é um processo onde os professores de forma individual ou coletiva, influenciam seus colegas, melhoram suas práticas de ensino e aprendizagem, com o objetivo de expandir a aprendizagem dos alunos e a sua realização".

Na visão de Danielson (2006), algumas competências dos professores facilitam a aprendizagem dos alunos e refletem resultados práticos além do ambiente de aula, e isso se encontra diretamente relacionado ao seu perfil de liderança. Essa capacidade dos professores acaba por mobilizar e entusiasmar outros em favor de melhorias e do desenvolvimento do ambiente educacional em que atuam, agindo também como um estímulo motivador ao trabalho dos colegas e de outros agentes envolvidos no processo.

Ao passar a ser objeto de estudo no contexto educacional, a liderança envolve organizações públicas e privadas (POSNER; ROSENBERGER, 1997). Pires e Macêdo (2006), dizem que o desenho organizacional público, na perspectiva brasileira, é caracterizado por formas complexas e níveis hierárquicos múltiplos. $\mathrm{O}$ alto índice de burocracia existente em seu funcionamento é o que torna seus sistemas tão complexos.

Assim sendo, esta pesquisa destaca o papel de liderança a ser desempenhado pelos docentes de instituições de ensino superior na busca pelo seu desenvolvimento. A seção a seguir delineia o caminho metodológico percorrido.

\section{METODOLOGIA DA PESQUISA}

As escolhas metodológicas dependem essencialmente do objeto a ser estudado, sua natureza, e os objetivos determinados na pesquisa. Assim, pretendeu-se conhecer o perfil de liderança dos docentes dos cursos de Administração e Ciências Contábeis da UFCG Campus Sousa.

Trata-se de estudo quantitativo, de caráter exploratório e descritivo. O caráter exploratório pelo conhecimento do fenômeno estudado tal como se apresenta, explorando conceitos e cenários inseridos. Descritiva por observar, registrar, analisar e correlacionar eventos e fenômenos, não havendo alteração das variáveis e procurando perceber a 
regularidade em que o evento ocorre, sua ligação com outros, sua natureza e aspectos gerais (GIL, 1999).

Caracteriza-se também como estudo de caso. Yin (2010, p. 24) afirma que o estudo de caso é uma investigação empírica que analisa um fenômeno contemporâneo em profundidade e em seu contexto realista, essencialmente quando os limites entre os dois não são claramente evidentes.

\subsection{UNIVERSO DA PESQUISA E AMOSTRA}

O ambiente analisado foi a Universidade Federal de Campina Grande, sendo selecionados os professores dos cursos de Administração e Ciências Contábeis para compor o universo da pesquisa. O período da pesquisa de campo foi de aproximadamente 45 dias, quando foi aplicado o questionário com 27 docentes. A pesquisa utilizou-se de amostragem não probabilística, por acessibilidade.

\subsection{INSTRUMENTO DA COLETA DE DADOS}

O instrumento de coleta dos dados constituiu-se de um questionário. Antes da sua aplicação, os docentes assinaram um termo de consentimento livre e esclarecido.O instrumento adotado na pesquisa foi o Multifactor Leadership Questionnaire ${ }^{\circledR}$ - MLQ, elaborado por Bass e Avolio (1995) e utilizado por Bigliazzi (2007) para avaliar as perspectivas de liderança transformacional, transacional e não-transacional. Ele compõe-se de 45 assertivas que avaliam, por meio de uma escala do tipo Likert de cinco pontos, e a seguinte classificação: (0) de modo algum, (1) de vez em quando, (2) algumas vezes, (3) relativamente frequente e (4) frequentemente. A partir da escala, os docentes foram solicitados a informar o nível de concordância/discordância em relação às afirmações.

\subsection{TRATAMENTO E ANÁLISE DOS DADOS}

Os dados foram tratados a partir de medidas descritivas: cálculo da média e desvio padrão. Mattar (2001), lembra que a média é uma medida de tendência central de aplicação restrita à variáveis intervalares. Para encontrar uma medida da variabilidade ou dispersão na mesma escala de avaliação dos dados, toma-se a raiz quadrada da variância e a partir aí se tem o desvio padrão. 
Para a análise e interpretação dos dados, as assertivas foram separadas em fatores e atributos correspondentes a cada um deles, a partir da análise fatorial feita por Bigliazzi (2007). As 45 variáveis do MLQ se dividiram em Liderança Transformacional, Liderança Transacional e Não-Transacional. Os dados foram analisados quantitativamente, por meio de técnicas estatísticas e estão expostas na próxima seção desse trabalho.

\section{ANÁLISE E DISCUSSÃO DOS DADOS}

Para a análise e interpretação dos dados, realizou-se o levantamento das assertivas do MLQ (Multifactor Leadership Questionnaire®) para avaliação das dimensões da liderança, sendo divididas as questões em grupos de acordo com atributos correspondentes. As 45 variáveis do MLQ foram alinhadas com o objetivo de observar os fatores caracterizados como Liderança Transformacional, Transacional e Não-Transacional, como também os atributos relacionados respectivamente a cada um.

\subsection{FATOR - LIDERANÇA TRANSFORMACIONAL}

A dedicação e comprometimento com a organização, satisfação com o trabalho, e busca incessante para atingir o sucesso nos objetivos traçados, são características proporcionadas pelo estilo de liderança transformacional. Segundo Bass (1985), a liderança transformacional é caracterizada pela avaliação de quatro perspectivas que estão diretamente relacionadas: o carisma, como atributo e como comportamento, a inspiração motivacional, a estimulação intelectual e a consideração individual. Estas quatro perspectivas serão exploradas nesse estudo a partir de agora.

As assertivas que avaliam a liderança transformacional estão dispostas na Tabela 1 com seus respectivos resultados de média e desvio padrão (DP).

Tabela 1: Fator Liderança transformacional

\begin{tabular}{|c|c|c|c|c|}
\hline & Assertiva & Descrição & Média & DP \\
\hline \multirow{5}{*}{ 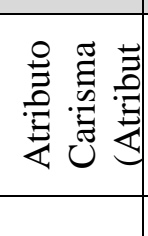 } & 10 & Gero orgulho por estarem do meu lado. & 2,78 & 0,70 \\
\hline & 18 & Vou além do interesse pessoal pelo bem do grupo. & 3,13 & 0,97 \\
\hline & 21 & Atuo de forma tal que consigo o respeito dos outros por mim & 2,93 & 0,98 \\
\hline & 25 & Demonstro um senso de poder e confiança. & 2,87 & 1,04 \\
\hline & & Média Geral & 2,93 & \\
\hline \multirow{5}{*}{ 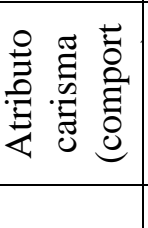 } & 6 & Converso sobre minhas crenças e valores mais importantes. & 2,37 & 0,74 \\
\hline & 14 & Mostro a importância de se ter um forte senso de obrigação. & 3,37 & 0,79 \\
\hline & 23 & Considero as consequências éticas e morais das decisões. & 3,52 & 0,51 \\
\hline & 34 & Enfatizo a importância de se ter um senso único de missão. & 2,31 & 1,09 \\
\hline & & Média Geral & 2,89 & \\
\hline
\end{tabular}




\begin{tabular}{|c|c|c|c|c|}
\hline \multirow{4}{*}{ 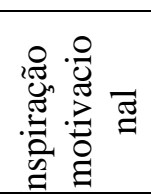 } & 9 & Falo de forma otimista sobre o futuro. & 3,30 & 0,78 \\
\hline & 13 & Falo com entusiasmo sobre o que precisa ser realizado. & 3,11 & 1,01 \\
\hline & 26 & Articulo uma visão positiva e motivadora a respeito do futuro. & 3,30 & 0,72 \\
\hline & 36 & Expresso confiança de que metas serão alcançadas. & 3,44 & 0,64 \\
\hline & & Média Geral & 3,29 & \\
\hline \multirow{5}{*}{ 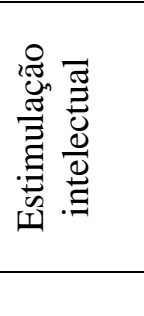 } & 2 & Examino situações críticas perguntando se são adequadas. & 2,85 & 0,83 \\
\hline & 8 & Procuro alternativas diferentes ao solucionar problemas. & 3,56 & 0,58 \\
\hline & 30 & $\begin{array}{l}\text { Faço com que os outros olhem para os problemas de diferentes } \\
\text { ângulos. }\end{array}$ & 3,15 & 0,77 \\
\hline & 32 & $\begin{array}{l}\text { Sugiro novas alternativas, maneiras de realizar e completar as } \\
\text { atividades. }\end{array}$ & 3,26 & 0,76 \\
\hline & & Média Geral & 3,21 & \\
\hline \multirow{4}{*}{ 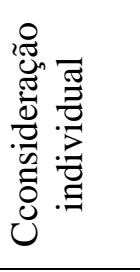 } & 15 & Invisto meu tempo ensinando e treinando. & 3,11 & 0,85 \\
\hline & 19 & $\begin{array}{l}\text { Trato os outros como pessoas ao invés de tratá-los apenas como } \\
\text { um membro do grupo. }\end{array}$ & 3,19 & 1,18 \\
\hline & 29 & $\begin{array}{l}\text { Considero cada pessoa como tendo necessidades, habilidades e } \\
\text { aspirações diferentes em relação aos outros. }\end{array}$ & 3,19 & 0,74 \\
\hline & 31 & Ajudo os outros no desenvolvimento de seus pontos fortes. & 3,07 & 0,73 \\
\hline
\end{tabular}

Fonte: Dados da Pesquisa (2016)

Quanto ao atributo carisma, o senso de missão se torna mais forte de acordo com o nível de carisma dos líderes. Ter uma equipe unida e com forte senso de missão mostra que o líder tem efetividade na realização de seu trabalho. Assim, as características do carisma são primordiais e mostram que os líderes devem ser carismáticos.

No atributo carisma (comportamento), os resultados indicam uma diferença considerável em relação à média. De acordo com Bass (1985), o carisma é o principal aspecto da liderança transformacional. A organização necessita de uma equipe de líderes com carisma elevado, pois isso gera uma relação entre seus membros de conforto e segurança, com resultados expressivos devido a confiança entre eles.

Bass (1985) diz que a inspiração motivacional, compreende a visão do líder e a comunicação desta visão para os seguidores, por meio de ações motivacionais, que geram altas expectativas, corrigem comportamentos e atitudes, com o objetivo de somar esforços. Os resultados da tabela 1 mostram que as assertivas obtiveram médias homogêneas e altas. Esse atributo irá trazer o espírito de equipe dentro da organização, construindo uma equipe coesa e coerente em busca de suas metas.

Em muitos momentos dentro da organização, os líderes são testados, tendo que provar sua capacidade em contornar e se adaptar à diversas situações e lidar com as adversidades. Daí a necessidade do atributo estimulação intelectual. Segundo Bass (1985), esse atributo 
refere-se à sugestão de desafios constantes aos seguidores, estimulando os mesmos à desenvolverem novas ideias e cenários. As características relacionadas são a criatividade, a flexibilidade e o poder de criar soluções inovadoras.

O atributo consideração individual faz com que cada seguidor tenha uma atenção personalizada, deixando-o se sentir único e aproximando o relacionamento. Esta perspectiva transpõe todas as outras, fazendo com que o líder atue como coach ou mentor. Essa característica permite ao líder elevar o nível de eficiência e eficácia da organização.

\subsubsection{FATOR - LIDERANÇA TRANSACIONAL}

A liderança transacional revela um líder em que se utiliza da legitimidade e autoridade à que lhe são conferidas para exercer o poder, constituindo práticas comuns a ênfase das regras e das normas estabelecidas para o cumprimento das tarefas previamente definidas (GOMES, 2005), sendo avaliada por meio de duas perspectivas: tamanho da recompensa e gerenciamento por exceção (ativo e passivo).

Esse perfil de líder não é recomendável para as organizações e não são vistos com bons olhos pela mesma, pois não estimulam a união e o espírito de grupo necessários para o cumprimento dos objetivos da instituição.

Tabela 2: Fator Liderança Transacional

\begin{tabular}{|c|c|c|c|c|}
\hline & Assertiva & Descrição & Média & DP \\
\hline \multirow{4}{*}{ 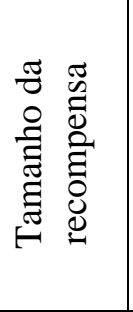 } & 1 & Forneço ajuda aos outros em troca de seus esforços. & 1,85 & 1,41 \\
\hline & 11 & $\begin{array}{l}\text { Discuto quem é o responsável por atingir metas específicas de } \\
\text { desempenho. }\end{array}$ & 2,27 & 0,92 \\
\hline & 16 & $\begin{array}{l}\text { Deixo claro o que cada um pode receber quando as metas de } \\
\text { desempenho são alcançadas. }\end{array}$ & 2,74 & 0,86 \\
\hline & 35 & $\begin{array}{l}\text { Expresso satisfação quando os outros correspondem às } \\
\text { expectativas. }\end{array}$ & 3,11 & 0,89 \\
\hline & & Média Geral & 2,49 & \\
\hline \multirow{5}{*}{ 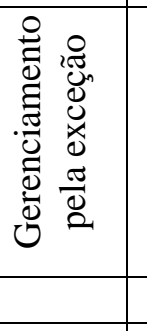 } & 4 & $\begin{array}{l}\text { Foco a atenção em irregularidades, erros, exceções e desvios dos } \\
\text { padrões esperados. }\end{array}$ & 2,33 & 1,11 \\
\hline & 22 & $\begin{array}{l}\text { Concentro minha total atenção em lidar com erros, reclamações e } \\
\text { falhas. }\end{array}$ & 2,26 & 0,90 \\
\hline & 24 & Mantenho-me a par de todos os erros. & 3,00 & 0,73 \\
\hline & 27 & Dirijo minha atenção às falhas. & 2,42 & 1,06 \\
\hline & & Média Geral & 2,50 & \\
\hline \multirow{4}{*}{ 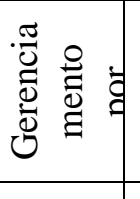 } & 3 & Não interfiro em problemas até o momento que se tornem sérios. & 1,63 & 1,08 \\
\hline & 12 & Espero as coisas darem errado para começar agir. & 0,56 & 0,77 \\
\hline & 17 & Demonstro acreditar que "não se mexe no que está dando certo". & 1,56 & 1,12 \\
\hline & 20 & Demonstro que os problemas devem tornar-se graves antes de agir. & 1,52 & 1,40 \\
\hline
\end{tabular}

Fonte: Dados da Pesquisa (2016) 
Quanto ao atributo tamanho da recompensa, Maximiano (2005) diz que a principal característica do líder transacional é oferecer recompensas materiais ao liderados. Smith e Peterson (1994) esclarecem que esta relação de troca entre as partes não é duradora, pois continuam até quando acreditam que esse tipo de relação está lhe trazendo benefício.

Os liderados irão trabalhar enquanto o líder oferece recompensas a eles. Quando o líder parar de recompensá-lo, ele não se sentirá mais motivado para exercer sua função e alcançar os objetivos da instituição que estará destinada ao insucesso com esse perfil de líder à sua frente, pois o mesmo não cria e desenvolve o valor da união e o espírito de grupo.

Em outro perfil, o líder interfere quando não existe sintonia entre as atividades que foram planejadas com as executadas. $O$ gerenciamento pela exceção pode ocorrer de maneira ativa e passiva, quando ele observa e procura pelos desvios das regras e dos padrões estabelecidos, tomando medidas corretivas quando estes são encontrados.

A pró-atividade entre os líderes pode ser representada por esse atributo. Desta forma, quanto maior for a pró-atividade do líder, maior a chance do grupo e da organização obterem sucesso, sendo este um atributo desejável para a organização.

O Gerenciamento por exceção passiva também pode ocorrer quando o líder interfere apenas quando algum erro acontece espontaneamente, devido não existir a busca pelos desvios acarretada pela suposta confiança de que os seguidores executarão suas atividades de maneira satisfatória. Esse perfil não é desejável nas organizações, pois se ficarem à mercê de líderes que não tenham a conduta proativa, podem ter seu desenvolvimento e seu futuro seriamente comprometidos.

\subsubsection{FATOR - LIDERANÇA NÃO TRANSACIONAL}

A avaliação deste estilo de liderança se dá através do atributo laissez-faire, no qual representa o próprio fator. Bass e Avolio (1992), destacam que caracteriza a atuação do líder como um mero figurante, evitando responsabilidade, resolver problemas e tomar decisões.

Este estilo de liderança não é desejável e pode-se mesmo ser considerado inconcebível na maioria das organizações, uma vez que toda e qualquer organização necessita de líderes com postura efetiva e diferenciada, que tomem decisões em momentos oportunos e inesperados. Líderes atuando como meros figurantes não são desejáveis. As assertivas que avaliam este atributo encontram-se na Tabela 3 . 
Tabela 3: Fator Liderança Não Transacional

\begin{tabular}{|c|c|c|c|c|}
\hline & Assertiva & Descrição & Média & DP \\
\hline & 5 & Evito me envolver quando assuntos importantes surgem. & 0,78 & 0,93 \\
\hline D. & 7 & Estou ausente quando necessitam de mim. & 0,48 & 0,64 \\
\hline ప్రు & 28 & Evito tomar decisões. & 0,70 & 1,10 \\
\hline & 33 & Demoro a responder as questões urgentes. & 1,42 & 1,24 \\
\hline
\end{tabular}

Fonte: Dados da Pesquisa (2016)

Os resultados indicam que entre os docentes pesquisados na UFCG, poucos se encaixam no perfil de liderança não transacional. Organizações públicas de ensino, que lidam com a educação das pessoas não podem de forma alguma ter líderes com estas características. Não se podem ter líderes omissos dentro da instituição, assim, os resultados com médias baixas neste atributo é satisfatório para a organização, visto que ele não é desejável.

\subsubsection{FATOR - FATORES DE RESULTADO}

Os Fatores de Resultados identificam a opinião do respondente em relação à sua atuação como líder e também os resultados que são alcançados através dela. Neste fator foram analisados dois atributos, o Esforço extra por sócios, Efetividade individual no grupo/organização e a satisfação como líder. Bass e Avolio (1995), dizem que o atributo esforço e efetividade refere-se ao esforço e a efetividade que o líder emprega no desempenho de seu papel.

Tabela 4: Fatores de Resultado

\begin{tabular}{|c|c|c|c|c|}
\hline & Assertiva & Descrição & Média & DP \\
\hline \multirow{7}{*}{ 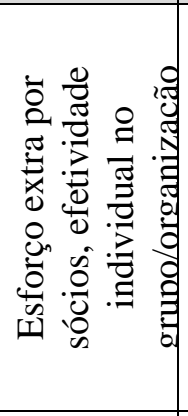 } & 39 & Faço com que os outros façam mais do que o esperado. & 2,59 & 0,75 \\
\hline & 42 & Elevo o desejo dos outros de obter sucesso. & 3,23 & 0,91 \\
\hline & 37 & $\begin{array}{l}\text { Sou eficaz em atender as necessidades dos outros em relação } \\
\text { ao trabalho. }\end{array}$ & 3,00 & 0,78 \\
\hline & 40 & $\begin{array}{l}\text { Sou eficaz em representar meu grupo perante níveis } \\
\text { hierárquicos superiores. }\end{array}$ & 2,96 & 0,82 \\
\hline & 43 & Sou eficaz em atender as necessidades da organização. & 3,19 & 0,74 \\
\hline & 45 & Lidero um grupo que é eficiente. & 2,96 & 0,87 \\
\hline & 38 & Utilizo métodos de liderança que são satisfatórios. & 2,81 & 0,83 \\
\hline & & Média Geral & 2,96 & \\
\hline \multirow{3}{*}{ 岕 } & 41 & Trabalho com os outros de maneira satisfatória. & 3,15 & 0,66 \\
\hline & 44 & $\begin{array}{l}\text { Aumento a vontade dos outros em trabalhar com maior } \\
\text { dedicação }\end{array}$ & 3,44 & 0,71 \\
\hline & & Média & 3,30 & \\
\hline
\end{tabular}

Fonte: Dados da Pesquisa (2016)

A tabela 4 apresenta as médias das assertivas. Isto quer dizer que, dentre os docentes 
que responderam à pesquisa, a maioria se esforça e tem satisfação no desenvolvimento das suas funções. O resultado obtido mostra que os líderes, em suas percepções, agem de maneira efetiva e esforçada, que é o que principalmente a organização precisa, empenho e determinação na busca do cumprimento dos objetivos.

O atributo satisfação como líder diz respeito a satisfação que o líder tem em relação ao cumprimento de seu papel na organização. Os resultados obtidos mostram que grande parte da amostra pesquisada é satisfeita em relação a isso, e ter líderes satisfeitos com seu trabalho é de grande valia, porque são seus esforços que vão determinar o futuro da organização.

\subsection{PERFIL DE LIDERANÇA DOS DOCENTES}

Para que todos os fatores analisados na pesquisa fossem representados, buscou-se chegar à uma média geral dos mesmos pelo cálculo das médias gerais das assertivas analisadas em cada fator, sendo feito o mesmo procedimento com o desvio padrão.

Gráfico1: Resultado da análise das assertivas do MLQ (Multifactor Leadership Questionnaire ${ }^{\circledR}$ ).

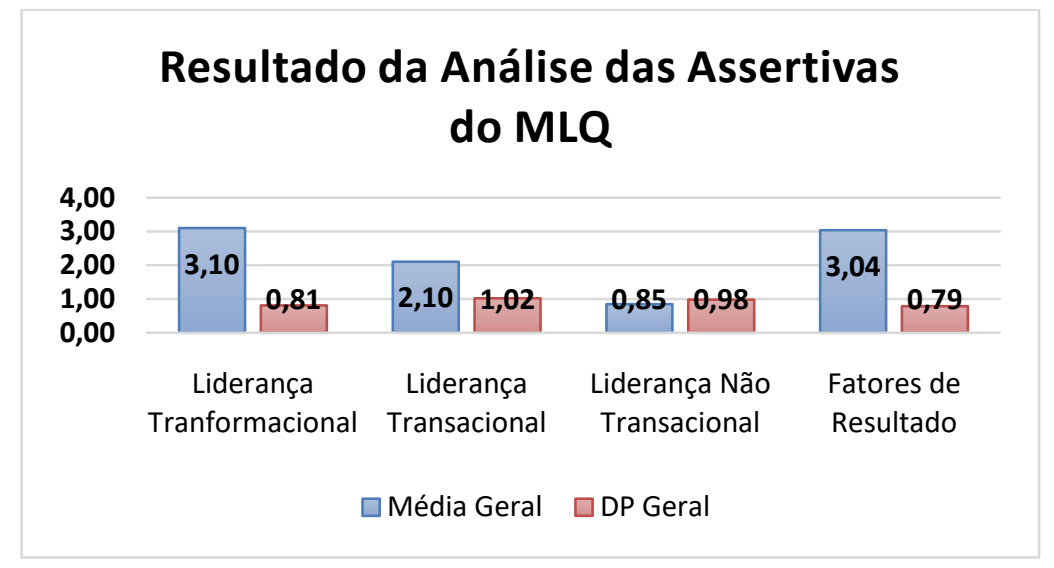

Fonte: Dados da Pesquisa (2016)

O estilo de liderança predominante entre os docentes analisados foi o estilo transformacional. Smith e Peterson (1994), afirmam que esta é preferível à liderança transacional sob toda e qualquer circunstância. Bass (1995), concorda que este estilo é o único que pode levar os liderados a executar suas atividades de forma extraordinária.

Independente da liderança transformacional ser a preferível entre todas as outras para as organizações, Bass e Avolio (1992) argumentam sobre a liderança transacional, no sentido de que não se pode desconsiderá-la, pois ela apenas limita o contato entre líder e liderado. 
Pelos resultados da pesquisa, a liderança transacional não foi maior que as outras abordagens analisadas, sendo visto assim como um ponto positivo para a organização.

Dentre as abordagens analisadas, a menos desejada nas organizações é a liderança não transacional. Na pesquisa, este estilo foi o que teve os menores resultados, indicando um fator positivo para a organização. A abordagem fatores de resultado configurou um ambiente favorável para que o líder exerça suas funções dentro da organização, o que mostra efetividade e satisfação.

\section{CONSIDERAÇÕES FINAIS}

O objetivo geral desse estudo foi conhecer o perfil de liderança dos docentes dos cursos de Administração e Ciências Contábeis da UFCG - Campus Sousa. Utilizou-se o questionário Multifactor Leadership Questionnaire ${ }^{\circledR}$ (Questionário Multifatorial de Liderança - MLQ), elaborado por Bass e Avolio (1995).

Os resultados obtidos mostraram que os atributos relacionados à Liderança Transformacional são os que definem o perfil dos docentes. Pode-se considerar este resultado como um fator positivo para a instituição, pois este estilo de liderança é o mais recomendável, por estimular o desenvolvimento do liderado de forma plena. Quanto à liderança transacional, ela não deve ser desconsiderada, pois somente limita o contato entre líder e liderados. Os fatores de resultados mostraram que o líder tem um ambiente favorável para desenvolver suas funções e que contribui para que a organização alcance seus resultados.

Desta forma, foram identificados os estilos de liderança predominantes e verificandose que os docentes possuem características de liderança que contribuem para que a organização alcance seus resultados. É de fundamental relevância para a instituição o trabalho em torno do desenvolvimento das competências de liderança dos docentes. A instituição poderá ter maior efetividade dos estilos desejáveis de liderança e consequentemente um aumento da eficiência e eficácia organizacional.

O estudo teve como limitação a dificuldade de entrevistar todos os docentes que fazem parte dos cursos de Administração e Ciências Contábeis, devido muitas vezes a incompatibilidade de horários. Para trabalhos futuros, sugere-se que se possa realizar um estudo com todos os docentes, não só dos cursos citados, mas de toda a instituição para uma melhor análise do perfil dos docentes da instituição como um todo. 


\section{REFERÊNCIAS}

BASS, B. M. (1985); Leadership and Performance beyond Expectations. New York: Free Press.

BASS, B. M.; AVOLIO, B. J. Developing Transformational Leadership: 1992 and beyond. Journal of European industrial training, v. 14, n. 5, 1990. Disponível em:

<http://search.ebscohostcom>.

BENNIS, Warren. A formação do líder. São Paulo: Atlas, 1996.

BERGAMINI, C. W. Liderança: Administração do Sentido. São Paulo: Atlas, 2009.

BIGLIAZZI, Samanta M. Luchini. Liderança e Formação Acadêmica - Uma Análise da Contribuição dos Cursos de Pós-Graduação Lato-Sensu em Gestão na Opinião dos Alunos. 2007. 139 f. Dissertação (Mestrado em Administração) - Universidade Municipal de São Caetano do Sul.

BOWDITCH, J. L.; BUONO, A. F. Elementos do comportamento organizacional. São Paulo: Pioneira Thomson, 2002.

DANIELSON, C. Teacher leadership that strengthens professional practice. ASCD, 2006.

GIL, Antonio Carlos. Pesquisa Social. São Paulo: Atlas, 1999.

GOMES, A. R. S. Liderança e relação treinador-atleta em contextos desportivos. 2005. 382 f. Tese (Doutorado em Psicologia). Universidade do Minho, Minho.

MAXIMIANO, A. C. A. Teoria Geral da Administração: da revolução urbana a revolução digital. 5. ed. São Paulo: Atlas, 2005.

MONTANA, J. P.; CHARNOV, H. B. Administração. São Paulo: Saraiva, 1998.

PIRES, J. C. S.; MACÊDO, K. B. Cultura organizacional em organizações públicas no Brasil. RAP, Rio de Janeiro, 40(1):81-105, Jan./Fev. 2006.

POSNER, B. Z.; ROSENBERGER, J.. Effective orientation advisors are also leaders. Journal of Student Affairs Research and Practice, v. 35, n. 1, p. 46-56, 1997.

SANT’ANNA, A. S., VAZ, S. L., NELSON, R. E., CAMPOS, M. S.; LEONEL, J. N.. Liderança: uma análise sob a perspectiva de acadêmicos brasileiros e norte-americanos. In: Encontro da ANPAD, 33, 2009, São Paulo. Anais... São Paulo: 2009b.

SMITH, P. B.; PETERSON, M. F. Liderança, Organizações e Cultura: Modelo de Administração do Evento. São Paulo: Pioneira, 1994. 
TRIGO, J. R.; COSTA, J.A. Liderança nas organizações educativas: a direção por valores. Ensaio: Avaliação de Políticas Públicas Educacionais. Rio de Janeiro, v. 16, n. 61, p. 561582, out./dez. 2008.

VAN SETERS, D. A.; FIELD, R. H. G. The evolution of leadership theory. V. 3, n.3. Journal of Organizational Management, 1990.

VERGARA, S. C. Gestão de Pessoas. São Paulo: Atlas, 2003.

WHITAKER, P. Gerir a mudança nas escolas. Porto: ASA, 2000.

YIN, Robert K. Estudo de Caso: planejamento e métodos. 4 ed. Porto Alegre: Bookman, 2010.

YORK-BARR, J.; DUKE, K. What do we know about teacher leadership? Findings from two decades of scholarship. Review of educational research, v. 74, n. 3, p. 255-316, 2004.

ZANOTTO, M. P. et al. Análise dos comportamentos e práticas de liderança docente em uma universidade brasileira. Espacios. v. 37, n. 10, 2016, p. E-2. 